\title{
DAPSONE TREATMENT OF LEPROSY
}

A. S. Garrett and M. G. Corcos

The following is a summary of 22 months experience of treatment of I0,000 patients with leprosy by Dapsone (D.A.D.P.S.) administered by mouth.

Treatment has been carried out in a central settlement of about $\mathrm{I}, 000$ patients and in 27 out-clinics, increasing during the period under review, to 39 .

Within the first 4 months those on treatment had reached about 5,000 and the total number has exceeded 10,000. During the period the medical staff has consisted of one to three doctors and one to six qualified nursing staff. The bulk of the work has fallen on lay workers who have been trained for the purpose. 
At the beginning all settlement patients were treated 6 days a week with a maximum dose of $0.2 \mathrm{gm}$. daily. The out-patients and patients in segregation villages were treated twice weekly with a maximum dose of $0.4 \mathrm{gm}$. After 6 months, it was apparent that, with the medical supervision available, the latter course gave much less complications. In Leprosy Review July-October, I95I, the routine treatment and early complications have been described. This present article gives more details of the effectiveness of this treatment and further details of all complications.

\section{Effectiveness of treatment.}

\section{Clinical.}

Nearly all tuberculoid cases are much improved. Lesions become flattened and about $60 \%$ of them regain their colour within I 8 months or so of starting treatment. The colour is more quickly regained in those lesions exposed to the sunlight. Also, as a general rule there seem to have been more rapid progress in those who have never had hydnocarpus oil than in those previously treated with it.

There remain a large group of patients whose macules appear completely flattened or wrinkled but in which the normal pigment has not returned or has returned only partly. Among these there are many who, near the beginning of treatment had new tuberculoid macules which have now subsided.

About ro to $15 \%$ of tuberculoid cases show continuous mild activity up to the present time. The macules remain slightly raised, but are not advancing.

About a dozen have had tuberculoid reactions of considerable proportions with increase of paralysis and deformity. Apart from these cases, nerve signs in tuberculoid leprosy have been absent or almost so.

In patients with lepromatous leprosy the improvement has been satisfactory. The great majority have improved without incident apart from very mild lepra reactions. About 10\% have had repeated lepra reactions and a further $10 \%$ have had repeated nerve reactions. In many of these, the dose has been reduced for a few months with satisfactory results. In others, removal of the nerve sheath has been followed by great improvement. I5 out of about 1,500 lepromas have been changed to thiacetazone treatment because of repeated reactions. Eye reactions have been rare and controlled by temporary reduction of dose, but 5 have been transferred to thiacetazone treatment.

\section{Bacteriological.}

In nearly all cases the bacterial improvement has been steady 
and well marked. As a routine 3 smears are taken and the result is tabulated as -ve to 4 + thus the maximum Bacteriological Index (B.I.) for a patient is $\mathrm{I} 2$.

The following is a group picked at random from several segregation villages to indicate the improvement.

\begin{tabular}{|c|c|c|c|c|c|c|c|c|c|c|c|}
\hline & & & B.I & & & & B.I & & & & B.I \\
\hline & & B.I & I.ast & & & R.I & L.ast & & & B.I & Last \\
\hline Pt's & No. & 1950 & Smear & Pt's & No. & 1950 & Smear & $\mathrm{Pt}^{\prime}$ & s No. & I 950 & Smear \\
\hline$A M$ & 50 & 9 & 2 & J & 220 & 2 & 0 & () & 825 & 6 & $\mathbf{I}$ \\
\hline, & 68 & 7 & 3 & J & 2361 & 12 & I0 & i) & 884 & 7 & 4 \\
\hline ,. & 70 & 8 & 4 & AN & 23 & 5 & 6 & () & 887 & 2 & I \\
\hline , & 127 & 8 & () & $\mathrm{AN}$ & 107 & 3 & 0 & 1) & $108 \mathrm{I}$ & 5 & o \\
\hline ", & 137 & 7 & 4 & AN & 112 & 3 & () & () & $115^{8}$ & 12 & I I \\
\hline ", & 146 & 5 & I & U & 96 & 2 & 0 & (i & I I I & I0 & 6 \\
\hline , & 162 & 9 & 5 & 1) & 132 & 8 & I & C & 137 & 2 & 0 \\
\hline F & 79 & 2 & 2 & I) & 236 & 7 & 3 & (i) & 176 & 2 & I \\
\hline $\mathrm{F}$ & I 17 & 3 & 4 & I) & $44^{2}$ & 4 & I & $G$ & 227 & 5 & 2 \\
\hline F & 229 & 3 & c) & U & 538 & 4 & 5 & (i) & +28 & 2 & 3 \\
\hline
\end{tabular}

\section{Trophic lesions.}

New trophic lesions have been uncommon but there is no evidence that dapsone has any considerable effect on existing trophic lesions. Gangrene, ascending from a trophic ulcer has been much rarer than under hydnocarpus oil. This may be due to the control of the bacteria of sepis by the dapsone.

\section{Drug Intolerance.}

The general health of the patients is much improved, but a few have shown signs of intolerance. Dermatitis has affected 2 to $3 \%$ of patients; this is often accompanied by enlargement of the liver and occasionally by jaundice. As previously reported 4 died out of the first 2,000 treated. Two have subsequently died. About ro have proved very difficult to desensitise and 4 of these have been transferred to thiacetazone treatment. In many cases the leprosy has markedly improved after an attack of dermatitis and in some the signs of disease have completely disappeared. These, if difficult to desensitise, have been discharged from treatment rather than risk a renewal of drug sensitivity, but one such patient has renewed tuberculoid activity.

Psychosis has affected about 50 people. Most of these were from among the I, 0oo patients who received daily treatment for the first 6 months, though cases are still occurring. Six have had psychotic symptoms for several months and appear likely to continue. The others have recovered after 2 or 3 months off treatment, after which treatment has been renewed. 